\title{
Spectrum of non-motor neuropsychiatric symptoms among patients with Parkinson's disease and Parkinson plus syndrome
}

\author{
Verma VK ${ }^{1}$, Anoop Kumar ${ }^{2}$, Singh $\mathrm{RR}^{3}$, Uraiya $\mathrm{D}^{4}$, Tripathi $\mathrm{N}^{5}$ \\ ${ }^{1,2,4,5}$ Assistant Professor, ${ }^{3}$ Associate Professor; all authors are attached with Department of Medicine, Hind Institute of \\ Medical Science, Safidabad, Barabanki, U.P, India.
}

Address for Correspondence: Dr Anoop Kumar, Assistant Professor, Department of Medicine, Hind Institute of Medical Science, Safidabad, Barabanki, U.P.

\begin{abstract}
Introduction: Patients with PD often have non motor symptoms in addition to the motor manifestations of bradykinesia, rigidity and tremor. The NMSs are more often seen in patients with longer duration of disease. There is increasing realization that NMSs significantly contribute to the morbidity and increase the burden of the disease far beyond that caused by the classical motor symptoms. Material and methods: It was a cross sectional study conducted to assess the non-motor dysfunction in 60 patients with Parkinsonism including idiopathic Parkinson's disease and Parkinson plus syndrome who attended either the outdoor services, or were admitted in the Neurology ward of our tertiary care centre, PGIMER \& Dr. RML Hospital, New Delhi, India. Results: Out of 40 patients with Parkinson's disease, twenty-five $(62.50 \%)$ were males and $15(37.50 \%)$ were females with mean age of 55.02 (SD \pm 13.56$)$ years. Among patients with MSA, six $(66.70 \%)$ were male and $3(33.33 \%)$ were female with mean age of 62.00 (SD \pm 11.38 ) years. Out of 40 patients with PD $19(47.50 \%)$ had minimal depression, 12 (30\%) mild depression, 7 (17.50\%) moderate depression and 2 (5\%) severe depression. Out of 20 patients with Parkinson plus Syndrome 12 (60\%), 5 (25\%), and 3 (15\%) patients had minimal, mild and moderate depression. Conclusion: Parkinson's disease and Parkinson plus syndrome are group of sporadic, neurodegenerative diseases of the central nervous system. There are only a few reports about the frequency of neuropsychiatric symptoms in patients with Parkinson disease from India and no such Indian report in patients with Parkinson plus syndrome
\end{abstract}

Keywords: Parkinsons disease, Non motor symptoms, Parkinson plus syndrome, Neuropsychiatric symptoms.

\section{Introduction}

Parkinson's disease (PD) is a common neurodegenerative disorder second only to Alzheimer's disease [1]. The cardinal clinical features of PD include asymmetric onset bradykinesia, rigidity and rest tremor [2]. The peak age of onset of PD is in the early 60s (range 35-85 years), and the course of illness ranges from 10 to 25 years [3]. The Parkinson's disease result from the loss of dopaminergic neurons in substantia nigra pars compacta [4]. Among the subjects with clinical features of Parkinsonism, approximately 80$85 \%$ have PD and the rest are Parkinson Plus Syndrome and secondary Parkinsonism [5]. Patients with PD often have non motor symptoms in addition to the motor manifestations of bradykinesia, rigidity and

Manuscript received $28^{\text {th }}$ June 2016

Reviewed: $7^{\text {th }}$ July 2016

Author Corrected: $18^{\text {th }}$ July 2016

Accepted for Publication ${ }^{\text {rd }}$ August 2016 tremor. The NMSs are more often seen in patients with longer duration of disease [6].

Clinical studies have shown that sensory symptoms, such as pain and anosmia, may precede the development of PD, sometimes by many years [7]. Central pain is usually associated with lesions in thalamus, and the intralaminar nuclei of thalamus which participate in the perception of pain, have major input to the basal ganglia [8]. Autonomic dysfunction occurs prominently in PD. This can manifest as dysphagia, constipation, urinary urgency, incontinence, erectile dysfunction, orthostatic hypotension, dyshidrosis, and impaired thermoregulation. About nine out of ten patients with PD have one or more of these autonomic symptoms [9]. Autonomic problems appear to increase significantly with increasing disease severity [10]. 
Parkinson plus syndrome is a group of sporadic, neurodegenerative diseases of the central nervous system, less common and usually more severe than Parkinson's disease. The most common forms are multiple system atrophy (MSA), progressive supranuclear palsy (PSP), corticobasal degeneration (CBD) and dementia with Lewy bodies (DLB).

They are characterised by relatively rapid disease progression and the presence of features that are atypical for PD, such as early postural instability and dementia, severe autonomic failure, or pyramidal and cerebellar signs [11].

There are only a few reports about the frequency of non-motor symptoms in patients with Parkinson Disease from India and no such Indian report in patients with Parkinson plus syndrome. Our study aimed to investigate the spectrum of non-motor symptoms among PD and Parkinson plus syndrome patients presenting to our tertiary care centre.

\section{Material and methods}

Study design: Cross-sectional

Study population: The study was conducted to assess the non-motor dysfunction in 60 patients with Parkinsonism including idiopathic Parkinson's disease and Parkinson plus syndrome who attended either the outdoor services, or were admitted in the Neurology ward of our tertiary care centre, PGIMER \& Dr. RML Hospital, New Delhi, India.

Inclusion criteria: Patients with Parkinsonism disease.

\section{Exclusion criteria:}

1. Systemic conditions known to be associated with autonomic dysfunction including diabetes, chronic alcoholism, chronic renal failure, chronic liver disease.

2. Patients with essential tremor.
3. Patients with secondary parkinsonism.

4. Severe cognitive dysfunction such that the relevant questionnaires for assessment cannot be undertaken by the patient.

5. Refusal to give consent for study.

\section{Methodology}

1. The study was approved by the Institutional Review Board of PGIMER \& Dr. RML Hospital, New Delhi, India.

2. A written informed consent was taken from all subjects before inclusion in the study.

3. After collecting the demographic data, all patients were subjected to comprehensive workup including history, general physical examination, and neurological examination.

4. They underwent routine investigations including complete blood counts, blood sugar (Fasting \& Postprandial), serum creatinine, total serum bilirubin, serum transaminases, serum electrolytes (sodium, potassium, and calcium), resting electrocardiogram, and neuroimaging (CT Scan Head and / or MRI Brain).

5. The patients were classified as Parkinson disease and Parkinson plus syndrome based on their clinical presentation.

6. Diagnosis of PD was made as per UK Brain Bank criteria [12].

7. Psychiatric and behavioural disorder was assessed by BDI-II (Beck Depression Inventory-II) [13] and NPI (Neuropsychiatric Inventory). [14].

8. Patients were classified into two groups based on age at onset ( $\leq 40$ years and $>40$ years), three groups based on disease duration ( $<2$ years, 2-5 years and $\geq 5$ years) and three groups based on disease severity (mild, moderate and severe) [15].

\section{Results}

Out of 40 patients with Parkinson's disease, twenty-five (62.50\%) were males and $15(37.50 \%)$ were females with mean age of 55.02 ( $\mathrm{SD} \pm 13.56$ ) years as shown in table 1 . Among patients with MSA, six (66.70\%) were male and $3(33.33 \%)$ were female with mean age of $62.00(\mathrm{SD} \pm 11.38)$ years.

Among patients with PSP, four (50.00\%) were male and 4 (50.00\%) were female with mean age of 62.37 (SD \pm 10.25$)$ years while all the three patients with DLB were male having mean age of 65.33 (SD \pm 12.34 ) years . 
Table-1: Clinical profile of sample population.

\begin{tabular}{|c|c|c|c|c|c|c|c|}
\hline & & $\begin{array}{c}\text { PD } \\
(n=40)\end{array}$ & $\begin{array}{l}\text { DLB } \\
(n=3)\end{array}$ & $\begin{array}{l}\text { MSA } \\
(n=9)\end{array}$ & $\begin{array}{l}\text { PSP } \\
(n=8)\end{array}$ & $\begin{array}{c}\text { PPS } \\
(n=20)\end{array}$ & $\begin{array}{c}\text { p value } \\
\text { (PD vs } \\
\text { PPS) }\end{array}$ \\
\hline \multirow{2}{*}{$\begin{array}{c}\text { Age at onset } \\
{[\text { Frequency }(\%)]}\end{array}$} & $\begin{array}{l}\leq 40 \\
\text { Yrs }\end{array}$ & $\begin{array}{c}5 \\
(12.50)\end{array}$ & $\begin{array}{c}0 \\
(0 \%)\end{array}$ & $\begin{array}{c}0 \\
(0 \%)\end{array}$ & $\begin{array}{c}0 \\
(0 \%)\end{array}$ & $\begin{array}{c}0 \\
(0 \%)\end{array}$ & \\
\hline & $\begin{array}{l}>40 \\
\text { Yrs }\end{array}$ & $\begin{array}{c}35 \\
(87.50 \%)\end{array}$ & $\begin{array}{c}3 \\
(100 \%)\end{array}$ & $\begin{array}{c}9 \\
(100 \%)\end{array}$ & $\begin{array}{c}8 \\
(100 \%)\end{array}$ & $\begin{array}{c}20 \\
(100 \%)\end{array}$ & \\
\hline \multicolumn{2}{|c|}{ Duration of Disease $[$ Mean \pm SD] } & $\begin{array}{c}2.09 \pm \\
1.82\end{array}$ & $\begin{array}{c}3.17 \pm \\
0.29\end{array}$ & $\begin{array}{c}2.67 \pm \\
1.52\end{array}$ & $\begin{array}{c}1.90 \pm \\
1.11\end{array}$ & $\begin{array}{c}2.43 \pm \\
1.29\end{array}$ & 0.455 \\
\hline \multirow{3}{*}{$\begin{array}{c}\text { Distributed Duration of } \\
\text { Disease } \\
{[\text { Frequency }(\%)]}\end{array}$} & $\begin{array}{l}2 \\
\text { yrs }\end{array}$ & $\begin{array}{c}19 \\
(47.5 \%)\end{array}$ & $\begin{array}{c}0 \\
(0 \%) \\
\end{array}$ & $\begin{array}{c}4 \\
(44.4 \%) \\
\end{array}$ & $\begin{array}{c}3 \\
(37.5 \%)\end{array}$ & $\begin{array}{c}7 \\
(35 \%) \\
\end{array}$ & \\
\hline & $\begin{array}{l}2-5 \\
\text { yrs }\end{array}$ & $\begin{array}{c}19 \\
(47.5 \%)\end{array}$ & $\begin{array}{c}3 \\
(100 \%)\end{array}$ & $\begin{array}{c}5 \\
(55.6 \%)\end{array}$ & $\begin{array}{c}5 \\
(62.5 \%)\end{array}$ & $\begin{array}{c}13 \\
(65 \%)\end{array}$ & \\
\hline & $\begin{array}{l}>5 \\
\text { yrs }\end{array}$ & $\begin{array}{c}2 \\
(5 \%)\end{array}$ & $\begin{array}{c}0 \\
(0 \%)\end{array}$ & $\begin{array}{c}0 \\
(0 \%)\end{array}$ & $\begin{array}{c}0 \\
(0 \%)\end{array}$ & $\begin{array}{c}0 \\
(0 \%)\end{array}$ & \\
\hline \multicolumn{2}{|l|}{ UPDRS (III) } & $\begin{array}{l}22.10 \\
\pm 5.83\end{array}$ & $\begin{array}{l}27.00 \\
\pm 3.00\end{array}$ & $\begin{array}{l}22.88 \\
\pm 9.78\end{array}$ & $\begin{array}{l}26.00 \\
\pm 4.50\end{array}$ & $\begin{array}{l}24.75 \\
\pm 7.20\end{array}$ & 0.131 \\
\hline
\end{tabular}

Table- 2: Distribution of patients according to severity of disease (Modified $H$ \& Y staging).

\begin{tabular}{|c|c|c|c|c|c|c|}
\hline \multicolumn{2}{|c|}{ Parameter } & $\begin{array}{c}\text { PD } \\
(n=40)\end{array}$ & $\begin{array}{l}\text { DLB } \\
(n=3)\end{array}$ & $\begin{array}{l}\text { MSA } \\
(n=9)\end{array}$ & $\begin{array}{c}\text { PSP } \\
(n=8)\end{array}$ & $\begin{array}{c}\text { PPS } \\
(\mathbf{n}=20)\end{array}$ \\
\hline \multirow{3}{*}{$\begin{array}{l}\text { Disease Severity } \\
\text { [Frequency }(\%)]\end{array}$} & $\begin{array}{l}\text { Mild (1-2) } \\
\quad(n=17)\end{array}$ & $\begin{array}{c}16 \\
(40 \%)\end{array}$ & $\begin{array}{c}0 \\
(0 \%)\end{array}$ & $\begin{array}{c}1 \\
(11.1 \%)\end{array}$ & $\begin{array}{c}0 \\
(0 \%)\end{array}$ & $\begin{array}{c}1 \\
(5 \%)\end{array}$ \\
\hline & $\begin{array}{l}\text { Moderate }(2.5-3) \\
(n=29)\end{array}$ & $\begin{array}{c}20 \\
(50 \%)\end{array}$ & $\begin{array}{c}3 \\
(100 \%)\end{array}$ & $\begin{array}{c}5 \\
(55.6 \%)\end{array}$ & $\begin{array}{c}1 \\
(12.5 \%)\end{array}$ & $\begin{array}{c}9 \\
(45 \%)\end{array}$ \\
\hline & $\begin{array}{c}\text { Severe (4-5) } \\
(n=14)\end{array}$ & $\begin{array}{c}4 \\
(10 \%)\end{array}$ & $\begin{array}{c}0 \\
(0 \%)\end{array}$ & $\begin{array}{c}3 \\
(33.3 \%)\end{array}$ & $\begin{array}{c}7 \\
(87.5 \%)\end{array}$ & $\begin{array}{c}10 \\
(50 \%)\end{array}$ \\
\hline
\end{tabular}

Table-3: Distribution of patients according to depression as per BDI-II score.

\begin{tabular}{|c|c|c|c|c|c|c|}
\hline \multicolumn{2}{|c|}{ DEPRESSION } & \multirow{2}{*}{$\begin{array}{c}\begin{array}{c}\text { PD } \\
(n=40)\end{array} \\
19\end{array}$} & \multirow{2}{*}{$\begin{array}{c}\begin{array}{c}\text { DLB } \\
(\mathbf{n}=3)\end{array} \\
0\end{array}$} & \multirow{2}{*}{$\begin{array}{c}\begin{array}{c}\text { MSA } \\
(\mathbf{n}=9)\end{array} \\
9\end{array}$} & \multirow{2}{*}{$\begin{array}{c}\begin{array}{c}\text { PSP } \\
(\mathbf{n}=8)\end{array} \\
3\end{array}$} & \multirow{2}{*}{$\begin{array}{c}\begin{array}{c}\text { PPS } \\
(\mathbf{n}=\mathbf{2 0})\end{array} \\
12\end{array}$} \\
\hline Minimal (0-9) & Frequency & & & & & \\
\hline & $\%$ & $47.50 \%$ & $0.00 \%$ & $100.00 \%$ & $37.50 \%$ & $60.00 \%$ \\
\hline \multirow{2}{*}{$\begin{array}{l}\text { Mild (10-18) } \\
\quad(n=17)\end{array}$} & Frequency & 12 & 3 & 0 & 2 & 5 \\
\hline & $\%$ & $30.00 \%$ & $100.00 \%$ & $0.00 \%$ & $25 \%$ & $25.00 \%$ \\
\hline \multirow{2}{*}{$\begin{array}{c}\text { Moderate (19-29) } \\
(\mathrm{n}=10)\end{array}$} & Frequency & 7 & 0 & 0 & 3 & 3 \\
\hline & $\%$ & $17.50 \%$ & $0.00 \%$ & $0.00 \%$ & $37.50 \%$ & $15.00 \%$ \\
\hline \multirow{2}{*}{$\begin{array}{c}\text { Severe } \\
(30-69) \\
(n=2)\end{array}$} & Frequency & 2 & 0 & 0 & 0 & 0 \\
\hline & $\%$ & $5.00 \%$ & $0.00 \%$ & $0.00 \%$ & $0.00 \%$ & $0.00 \%$ \\
\hline
\end{tabular}

Out of 40 patients with PD 19 (47.50\%) had minimal depression, 12 (30\%) mild depression, 7 (17.50\%) moderate depression and $2(5 \%)$ severe depression. Out of 20 patients with Parkinson plus Syndrome 12 (60\%), 5 (25\%), and 3 (15\%) patients had minimal, mild and moderate depression (table 3). 
Table- 4: Distribution of neuropsychiatric symptoms as per NPI.

\begin{tabular}{|c|c|c|c|c|c|c|}
\hline \multicolumn{2}{|c|}{ NEUROPSYCHIATRIC SYMPTOM } & \multirow{2}{*}{$\begin{array}{c}\begin{array}{c}\text { PD } \\
(n=40)\end{array} \\
2\end{array}$} & \multirow{2}{*}{$\begin{array}{c}\begin{array}{c}\text { DLB } \\
(\mathbf{n}=3)\end{array} \\
1\end{array}$} & \multirow{2}{*}{$\begin{array}{c}\begin{array}{c}\text { MSA } \\
(\mathbf{n}=9)\end{array} \\
0\end{array}$} & \multirow{2}{*}{$\begin{array}{c}\begin{array}{c}\text { PSP } \\
(\mathbf{n}=\mathbf{8})\end{array} \\
0\end{array}$} & \multirow{2}{*}{$\begin{array}{c}\begin{array}{c}\text { PPS } \\
(\mathbf{n}=\mathbf{2 0})\end{array} \\
1\end{array}$} \\
\hline Delusion & Frequency & & & & & \\
\hline & $\%$ & $5.00 \%$ & $33.33 \%$ & $0.00 \%$ & $0.00 \%$ & $5.00 \%$ \\
\hline \multirow[t]{2}{*}{ Hallucination } & Frequency & 2 & 2 & 0 & 0 & 2 \\
\hline & $\%$ & $5.00 \%$ & $66.67 \%$ & $0.00 \%$ & $0.00 \%$ & $10.00 \%$ \\
\hline \multirow[t]{2}{*}{ Aggitation } & Frequency & 14 & 1 & 3 & 0 & 4 \\
\hline & $\%$ & $35.00 \%$ & $33.33 \%$ & $33.33 \%$ & $0.00 \%$ & $20.00 \%$ \\
\hline \multirow[t]{2}{*}{ Depression } & Frequency & 28 & 2 & 4 & 5 & 11 \\
\hline & $\%$ & $70.00 \%$ & $66.67 \%$ & $44.44 \%$ & $62.50 \%$ & $55.00 \%$ \\
\hline \multirow[t]{2}{*}{ Anxiety } & Frequency & 17 & 1 & 4 & 3 & 8 \\
\hline & $\%$ & $42.50 \%$ & $33.33 \%$ & $44.44 \%$ & $37.50 \%$ & $40.00 \%$ \\
\hline \multirow[t]{2}{*}{ Euphoria } & Frequency & 0 & 0 & 0 & 1 & 1 \\
\hline & $\%$ & $0.00 \%$ & $0.00 \%$ & $0.00 \%$ & $12.50 \%$ & $5.00 \%$ \\
\hline \multirow[t]{2}{*}{ Appetite } & Frequency & 11 & 0 & 3 & 2 & 5 \\
\hline & $\%$ & $27.50 \%$ & $0.00 \%$ & $33.33 \%$ & $25.00 \%$ & $25.00 \%$ \\
\hline \multirow[t]{2}{*}{ Apathy } & Frequency & 14 & 2 & 2 & 7 & 11 \\
\hline & $\%$ & $35.00 \%$ & $66.67 \%$ & $22.22 \%$ & $87.50 \%$ & $55.00 \%$ \\
\hline \multirow[t]{2}{*}{ Disinhibition } & Frequency & 1 & 0 & 0 & 2 & 2 \\
\hline & $\%$ & $2.50 \%$ & $0.00 \%$ & $0.00 \%$ & $25.00 \%$ & $10.00 \%$ \\
\hline \multirow[t]{2}{*}{ Irritability } & Frequency & 15 & 2 & 3 & 2 & 7 \\
\hline & $\%$ & $37.50 \%$ & $66.67 \%$ & $33.33 \%$ & $25 \%$ & $35.00 \%$ \\
\hline \multirow[t]{2}{*}{ Lability } & Frequency & 11 & 1 & 5 & 3 & 9 \\
\hline & $\%$ & $27.50 \%$ & $33.33 \%$ & $55.55 \%$ & $37.50 \%$ & $45.00 \%$ \\
\hline \multirow{2}{*}{$\begin{array}{c}\text { Motor } \\
\text { Disturbance }\end{array}$} & Frequency & 0 & 0 & 1 & 1 & 2 \\
\hline & $\%$ & $0.00 \%$ & $0.00 \%$ & $11.11 \%$ & $12.50 \%$ & $10.00 \%$ \\
\hline \multirow[t]{2}{*}{ Night behaviors } & Frequency & 25 & 1 & 6 & 4 & 11 \\
\hline & $\%$ & $62.50 \%$ & $33.33 \%$ & $66.67 \%$ & $50.00 \%$ & $55.00 \%$ \\
\hline \multirow[t]{2}{*}{ Appetite } & Frequency & 11 & 0 & 3 & 2 & 5 \\
\hline & $\%$ & $27.50 \%$ & 0.005 & $33.33 \%$ & $25.00 \%$ & $25.00 \%$ \\
\hline
\end{tabular}

The common neuropsychiatric symptoms in PD patients were depression (70\%), night behaviours $(62.50 \%)$, anxiety (42.50\%), irritability (37.5\%) and apathy (35\%). In Parkinson Plus Syndrome patients were depression (55\%), night behaviours (55\%), apathy (55\%), lability (45\%), anxiety (40\%) and irritability (35\%) (table 6A \& 6B).

\section{Discussion}

Depression was observed in all the PD patients using BDI-II. Nineteen $(47.50 \%)$ had minimal, $12(30 \%)$ mild, $7(17.50 \%)$ moderate and $2(5 \%)$ had severe depression. There was significant correlation of depression with duration $(\mathrm{p}=0.027)$ of illness. Statistically significant correlation was found between depression and severity of disease when assessed by UPDRS-III $(p=0.003)$. Depression and severity of disease as assessed by modified $\mathrm{H} \& \mathrm{Y}$ scale were not observed to have statistically significant correlation $(\mathrm{p}=0.088)$. Neuropsychiatric symptoms using NPI were observed in all PD patients with $2(5 \%)$ reporting delusion, $2(5 \%)$ hallucination, $14(35 \%)$ agitation, 28 (70\%) depression, 17 (42.50\%) anxiety, no euphoria, 14 (35\%) apathy, 1 (2.5\%) disinhibition, 15 (37.5\%) irritability, $11(27.50 \%)$ lability, 25 (62.50\%) night behaviours and $11(27.50 \%)$ altered appetite.

Our finding is in concordance with previous literature. Rajinders JSAM et al. and Tan LCS reported major depressive disorder in $17 \%$, minor depressive disorder in $22 \%$, and dysthymia in $13 \%$ of their PD patients. They observed clinically significant depressive symptoms in $35 \%$ of PD patients $[16,17]$. Mayeux R 
reported major depression in $40 \%$ of PD patients [18] and Cummings JL reported prevalence rates ranging from $4 \%$ to $70 \%$ [19]. B. Ravina et al. reported that Depression can occur in up to $27.6 \%$ of PD patients during early stages of the disease [20].

In our study, 5\% of PD patients had hallucinations. Goetz CG reported hallucinations and delusions occur in up to $40 \%$ of PD patients and are a major reason for nursing home placement [21]. G. Fenelon and G. Alves reported that the prevalence of complex visual hallucinations ranges from 22 to $38 \%$ [22]. The lower prevalence of hallucinations and delusions in our study is probably because most patients came in early stage of disease with short disease duration and were not on any dopaminergic drugs.

We observed anxiety symptoms in $42.5 \%$ PD patients. Similar frequency of anxiety symptoms have been reported in earlier studies [23,24,25]. Apathy was observed in $35 \%$ PD subjects similar to previous studies wherein the frequency of apathy reportedly ranged from 30 to $40 \%$ [26, 27].

The spectrum and frequency of neuropsychiatric symptoms in our study were similar to that reported by other authors. Kulisevsky $\mathrm{J}$ et al. reported that the most common neuropsychiatric symptoms were depression (70\%), anxiety (69\%), apathy (48\%), and irritability $(47 \%)$ [28].

Neuropsychiatric symptoms observed in DLB patients were delusion in $1(33.33 \%)$, hallucination in 2 $(66.67 \%)$, agitation in $1(33.33 \%)$, depression in 2 $(66.67 \%)$, anxiety in $1(33.33 \%)$, apathy in $2(66.67 \%)$, irritability in $2(66.67 \%)$, emotional lability in 1 $(33.33 \%)$, night behaviour in 1 (33.33\%), with no altered appetite, motor disturbance, or disinhibition. Previous studies also report of similar findings in DLB individuals using NPI. McKeith. (2002) reported visual hallucinations (11-64)\%, auditory hallucination (13-30)\% and depression (7-75)\% [29], Fritze F et al. reported that $59 \%$ showed symptoms of depression and $25 \%$ had clinically significant depression [30]. Hirono $\mathrm{N}$ et al. reported $53.3 \%$ having hallucination, $73.3 \%$ delusions and least occurrence of euphoria and disinhibition [31].

In MSA patients, we observed agitation in $33.33 \%$, depression in $44.44 \%$, anxiety in $44.4 \%$, apathy in $22.22 \%$, irritability in $33.33 \%$, emotional lability in $55.56 \%$, motor disturbance in $11.1 \%$, night behaviour in
$66.66 \%$, altered appetite in $33.33 \%$ and no delusion, hallucination or disinhibition. Findings are consistent with previous data. Tiffany Nichole Reid (2011) reported of depression (56\%), apathy (48\%), agitation (27\%), anxiety (27\%), hallucinations (15\%), disinhibition $(13 \%)$, irritability $(10 \%)$, and delusions $(4 \%)$. Benrud-Larson et al. reported that approximately $80 \%$ had at least mild depressive symptoms and $39 \%$ had moderate to severe depression [32].

Patients with PSP reported had depression (62.50\%), anxiety $(37.50 \%)$, euphoria $(12.50 \%)$, apathy $(87.50 \%)$, disinhibition (25\%), irritability (25\%), labiality $(37.50 \%)$, motor disturbance $(12.50 \%)$, and night behaviour $(50 \%)$, altered appetite $(25 \%)$, with no hallucination, delusion or agitation. Litvan I et al.(1996) also reported similar findingsin 22 PSP patients reporting apathy $(91 \%)$, disinhibition $(36 \%)$, dysphoria $(18 \%)$ and anxiety $(18 \%)$, but rarely $(<9 \%)$ irritability, abnormal motor behaviors, or agitation. Hallucinations, delusions, and euphoria were never reported in PSP [33].

\section{Conclusion}

Parkinson's disease and Parkinson plus syndrome is a group of sporadic, neurodegenerative diseases of the central nervous system. The most common forms are multiple system atrophy (MSA), progressive supranuclear palsy (PSP), cortico-basal degeneration (CBD) and dementia with Lewy bodies (DLB). They are characterized by relatively rapid disease progression and the presence of features that are atypical for PD. In Parkinson plus syndrome survival time is shorter and more complications occur in earlier stages and with higher degree of severity than in PD. There are only a few reports about the frequency of neuropsychiatric symptoms in patients with Parkinson disease from India and no such Indian report in patients with Parkinson plus syndrome.

Funding: Nil, Conflict of interest: None initiated, Permission from IRB: Yes

\section{References}

1. Przedborski S. Etiology and pathogenesis of PD. In: Jankovic J, Tolosa E, eds. PD and Movement Disorders 5th ed. Philadelphia: Lippincott Williams and Wilkins; 2007;77-92.

2. Chaudhuri KR, Martinez-Martin P, Brown RG, Sethi

$\mathrm{K}$, Stocchi F, Odin P, et al. The metric properties of a 
novel non-motor symptoms scale for PD: results from an international pilot study. Mov Disord 2007;22:190111.

3. Delong MR, Juncos JL. PD and other extrapyramidal movement disorders. In: Fauci AS, Braunwald E, Kasper DL, Hauser SL, Longo DL, Jameson JL, et al., eds. Harrison's principles of internal medicine 17th ed. New York (NY): The McGraw-Hill Companies 2008; 2549-59.

4. Jankovic J, Shannon KM. Movement Disorders. In: Bradley WG, Daroff RB, Fenichel GM, Jankovic J, eds. Neurology in clinical practice 5th ed. Philadelphia: Butterworth-Heinemann, Elsevier; 2008;2081-122.

5. Mitra K, Gangopadhyaya PK, Das SK. Parkinsonism plus syndromes - A review. Neurology India 2003;5: 183-8.

6. Barone P, Antonini A, Colosimo C, et al., "The PRIAMO study: a multicenter assessment of nonmotor symptoms and their impact on quality of life in PD," Movement Disorders 2009; 24(11):1641-1649.

7. Witjas T, Kaphan E, Azulay JP. Non-motor fluctuations in PD: Frequent and disabling. Neurology 2002;59:408-413.

8. Berendse HW, Groenewegen HJ. Organization of the thalamostriatal projections in the rat, with a special emphasis on the ventral striatum. J Comp Neurol 1990; 299:187-228.

9. Singer C, Weiner WJ, Sanchez-Ramos J, Ackerman M. Sexual functions in patients with PD. J Neurol Neurourgery \& Psychiatry 1991;54(10):942.

10. Visser M, Marinus J, Stiggelbout AM, van Hilten JJ. Assessment of autonomic dysfunction in PD : The SCOPA- AUT. Mov Disord 2004;19(11):13061312.

11. Litvan I. Update on atypical parkinsonian disorders. Curr Opin Neurol 2007;20:434-437.

12. Hughes AJ, Daniel SE, Kilford L, Lees AJ. Accuracy of clinical diagnosis of idiopathic Parkinson's disease. A clinico-pathological study of 100 cases. JNNP 1992;55:181-184.

13. Beck AT, Steer R, Brown G. Beck Depression Inventory-II. San Antonio, TX: The Psychological Corporation; 1996.
14. Cummings JL, Mega M, Gray K, RosenbergThompson S, Carusi DA, Gornbein J. The neuropsychiatric inventory: comprehensive assessment of psychopathology in dementia. Neurology 1994;44: 2308-2314.

15. Schenkman ML, Clark K, Xie T, Kuchibhatla M, Shinberg M, Ray L. Spinal movement and performance of Standing Reach Task in participants with and without Parkinson Disease. Phys Ther. 2001;81(8):1400-11.

16. Reijnders JSAM, Ehrt U, Weber WEJ, Aarsland D, Leentjens AFG. "A systematic review of prevalence studies of depression in PD," Movement Disorders 2008;23(2):183-189.

17. L. C. S. Tan. Mood disorders in PD, Parkinsonism \& Related Disorders, vol. 18, supplement 2012;1:S74S76.

18. Mayeux R. The mental state in PD, in Handbook of PD, 2nd Edition. Edited by Koller WC. New York, Marcel Dekker 1992;159-184.

19. Cummings JL. Depression and PD. a review. Am J Psychiatry 1992;149:443-454.

20. Ravina B, Camicioli R, Como PG, et al. "The impact of depressive symptoms in early Parkinson disease," Neurology 2007;69(4):342-347.

21. Goetz CG, Stebbins GT. Risk factors for nursing home placement in advanced PD. Neurology 1993;43:2227-2229.

22. Fenelon $\mathrm{G}$ and Alves G. "Epidemiology of psychosis in PD," Journal of the Neurological Sciences 2010;289(1-2):12-17.

23. Marsh L. "Anxiety disorders in PD," International Review of Psychiatry 2000;12(4): 307-318.

24. Nuti A, Ceravolo R, Piccini A, et al., "Psychiatric comorbidity in a population of PD patients," European Journal of Neurology 2004;11(5)315-320.

25. Richard IH, Schiffer RB, Kurlan R. Anxiety and PD. J Neuropsychiatry Clin Neurosci 1996;8:383-392.

26. S. E. Starkstein, H. S. Mayberg, T. J. Preziosi, P. Andrezejewski, R. Leiguarda, and R. G. Robinson, "Reliability, validity, and clinical correlates of apathy in PD," Journal of Neuropsychiatry and Clinical Neurosciences 1992;4(2):134-139. 
27. P. Sockeel, K. Dujardin, D. Devos, C. Denève, A. Destee, and L. Defebvre. "The Lille apathy rating scale (LARS), a new instrument for detecting and quantifying apathy: validation in PD," Journal of Neurology, Neurosurgery and Psychiatry2006;77(5):579-584.

28. Kulisevsky J, Pagonabarrag J, Pascual-Sedano B, García-Sánchez C, Gironell A. Prevalence and correlates of neuropsychiatric symptoms in PD without dementia. Movement Disorders 2008; 23(13): 18891896.

29. McKeith. Dementia with Lewy bodies.The British Journal of Psychiatry 2002; 180: 144-147.

30. Fritze F, Ehrt U, SÃsnnesyn H, et al. Depression in mild dementia: associations with diagnosis, APOE genotype and clinical features. International Journal of Geriatric Psychiatry. 2011;26(10):1054-61.

31. Hirono $\mathrm{N}$, Mori $\mathrm{E}$, Imamura $\mathrm{T}$, Shimomura $\mathrm{T}$, Hashimoto M. Neuropsychiatric features in Dementia with Lewy bodies and Alzheimer's disease.No to Shinkei. 1998; 50(1):45-9.

32. Benrud-Larson LM, Sandroni P, Schrag A, Low PA. Depressive symptoms and life satisfaction in patients with multiple system atrophy. Mov Disord 2005; 20(8):951-7.

33. Litvan I., Mega M.S., Cummings J.L., Fairbanks L. Neuropsychiatric aspect of PSP. Neurology 1996; 47:1184-1189.

\section{How to cite this article?}

Verma VK, Anoop Kumar, Singh RR, Uraiya D, Tripathi N. Spectrum of non-motor neuropsychiatric symptoms among patients with Parkinson's disease and Parkinson plus syndrome. Int J Med Res Rev 2016;4(8):14041410.doi:10.17511/ijmrr.2016.i08.19. 